\title{
Multispecies functional response of the minke whale Balaenoptera acutorostrata based on small-scale foraging studies
}

\author{
Sophie Smout ${ }^{1, *}$, Ulf Lindstrøm ${ }^{2}$ \\ ${ }^{1}$ Sea Mammal Research Unit, Gatty Marine Laboratory, St. Andrews, Fife KY10 8LG, UK \\ ${ }^{2}$ Havforskingsinstituttet/Institute of Marine Research, Sykehusveien 23, PB 6404, 9294 Tromsø, Norway
}

\begin{abstract}
Atlantic minke whales are important predators in the Barents Sea ecosystem; capelin Mallotus villosus, krill Thysanoessa sp. and Meganyctephanes norvegica and herring Clupea harengus are their major prey. Their consumption of commercial species may present an economic problem for the local fishery. In order to estimate this consumption and understand the potential consequences for prey dynamics, it is essential to determine the multispecies functional response of the whales. The parameterisation of a functional response requires measurements of consumption rates and prey availability. In this localised study, undigested stomach contents were used to assess the amount of each prey that had been consumed immediately prior to capture. To determine the availability of prey to the whales, standard acoustic surveys were run in the same area within $2 \mathrm{~d}$ of the capture of the whales. The spatial distribution of prey was modelled using generalised additive models (GAMs). In order to generate a measure of prey availability and the uncertainty in this value, a simple model was assumed for whale movement, and prey abundance was sampled over space according to a Gaussian kernel. A multispecies functional response (MSFR) model was then fitted to the consumption and prey availability data using Bayesian methods. Simple simulations, based on the fitted MSFR, indicate that minke whales may deplete local capelin aggregations at small spatial scales. This is the first time that a multispecies functional response has been fitted for a cetacean predator, and the methods outlined here may prove useful for modelling marine mammal-fish interactions in other systems.
\end{abstract}

KEY WORDS: Functional response - Generalist predator $\cdot$ Minke whale $\cdot$ Baleonoptera acutorostrata Barents Sea

Resale or republication not permitted without written consent of the publisher

\section{INTRODUCTION}

The Barents ecosystem is a shallow, continental shelf sea of high productivity and low biological diversity (Hamre 1994, Sakshaug et al. 1994), and it is an important feeding area for several high trophic-level predators. Like most marine ecosystems, the Barents Sea has experienced major changes in species composition and abundance during the past decades: the collapses and subsequent recoveries of the stocks of Norwegian spring-spawning herring Clupea harrengus and Barents Sea capelin Mallotus villosus (Hamre 1994, Dragesund et al. 1997) are some examples.
These changes have had major ecological as well as economic consequences, and point to the need for a more holistic management of marine resources in the Barents Sea where inter- and intra-specific interactions as well as interactions between species and the environment are taken into consideration (Pikitch 2004). Trophic interactions form a crucial part of ecosystem models: consumption by predators has important consequences for the dynamics of both predator and prey populations and, in a complex ecosystem containing many generalists, multispecies interactions may result in counter-intuitive outcomes for predators and prey. An understanding of multi- 
species predatory interactions is therefore required to inform multispecies and eco-trophic models (Schweder et al. 1998, Yodzis 1998, Begley \& Howell 2004) in order to correctly model the Barents Sea ecosystem.

The minke whale Balaenoptera acutorostrata is one of the most conspicuous high trophic-level predators in the Barents Sea ecosystem (e.g. Haug et al. 2002, Tjelmeland \& Lindstrøm 2005). Quantifying the interaction strength between minke whales and their prey on various spatial and temporal scales is important for understanding their function in the Barents Sea ecosystem (e.g. IWC 2002, NAMMCO 2004). Assessment of predator-prey interactions is also important for the performance of multispecies and eco-trophic models by constraining the model parameters to be estimated (e.g. Yodzis 1998, Begley \& Howell 2004).

Behavioural responses of predators to temporal and spatial variability in prey abundance give rise to variations in diet and overall consumption rate. The relationship between consumption and prey abundance (i.e. the predator's functional response) can be summarised using a mathematical model such as the Holling Disc Equation (Holling 1959):

$$
C=\frac{\alpha N}{1+\alpha h N}
$$

where $C$ is the consumption rate of prey by the predator, $N$ is the abundance of prey, $\alpha$ represents the encounter rate between predators and prey, and $h$ is the handling time - the maximum rate at which a predator can consume prey.

The Holling Disc Equation has been modified to include more complex aspects of predator behaviour such as competition between predators (Abrams \& Ginzburg 2000). Informative reviews of the rich variety of functional responses are available (Jeschke et al. 2002, Gentleman et al. 2003), so we restrict ourselves here to very brief summary of some aspects relevant to the model that we used for the minke whale study.

Holling's Disc Equation represents a Type 2 functional response: a plot of $C$ against $N$ is hyperbolic, and predation mortality experienced by prey $(c / N)$ increases as $N$ decreases (solid curves in Fig. 1). If attack rate $a$ is allowed to vary with $N$, for example:

$$
\alpha=a N^{m}
$$

then the functional-response equation becomes:

$$
c=\frac{a N^{m}}{1+a h N^{m}}
$$

Where $C, N, h$ are as defined previously, $a$ is now a constant relation encounter rate to prey density, and the exponent $m$ is a 'shape parameter' that sets the shape of the resulting functional response curve (Real 1977). If $m>1$, then the curve becomes sigmoidal, and the functional response is referred to as a Type 3 functional response. Mortality is reduced at very low abundances of prey (dotted curves in Fig. 1). If $m=1$, then Eq. (3) is equivalent to Eq. (1) and the consumptionrate curve is a hyperbola. In the original formulation of this model, the change in attack rate with prey abundance was conceived as a predator response to aggregations of prey (Real 1979), but it is also possible to derive a Type 3 functional response equation in other ways, e.g. resulting from apostatic selection by predators, refuge use by prey or improvements in predator foraging efficiency when prey abundance is high (Dunbrack \& Liguere 1987).

Eqs. (1) \& (3) can both be re-formulated for generalists that consume multiple types of prey (Hilborn \& Walters 1992). When the equations are re-written in this way, single-species functional responses for individual prey species consumed in isolation can be recovered by setting the abundances of all other prey to zero; in this sense, it is still possible to refer to the functional response to a particular prey type as 'Type 2' or 'Type 3'. Parameter $\alpha$ can be re-interpreted as representing the relative preference of predators for different prey types, or the relative efficiency of predators at finding and capturing their diverse prey when $m=1$. When $m>1$, preference varies with $N$ and switching (in the sense of a change in preference) can occur.

The form of the functional response (whether Type 1 or Type 2) has important implications for coexistence of species and for predator-prey dynamics (e.g. Kotler \& Brown 1988, 1999, Vincent et al. 1996). Subtle differences in predation thresholds and prey preferences may promote coexistence of species that share food resources and dampen food-web oscillations (e.g. Murdoch \& Oaten 1975, Abrams 1999, Abrams \& Ginzburg 2000, van Baalen et al. 2001).

The present study estimates the functional response of northeast Atlantic minke whales by fitting a multispecies functional response (MSFR) model to diet and prey biomass data.

The whale samples were collected, in accordance with international law, from commercial whale catches in the southern Barents Sea in 1998 and 1999. When consumption is estimated by sampling stomach contents in this way, each predator can only be sampled once, and different predators are sampled under different conditions of prey availability in order to obtain an indication of the way in which individuals in general might respond to changes in the prey field i.e. the study is cross-sectional. The data resemble those used in other functional response studies in both terrestrial (Pech et al. 1992) and marine (Rindorf \& Gislason 2005) systems, and is of a different kind to that obtained in longitudinal studies where individual 


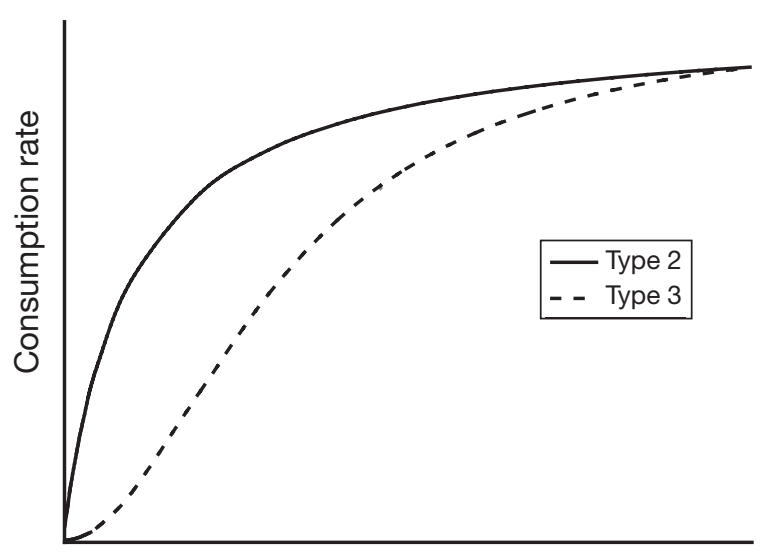

Abundance

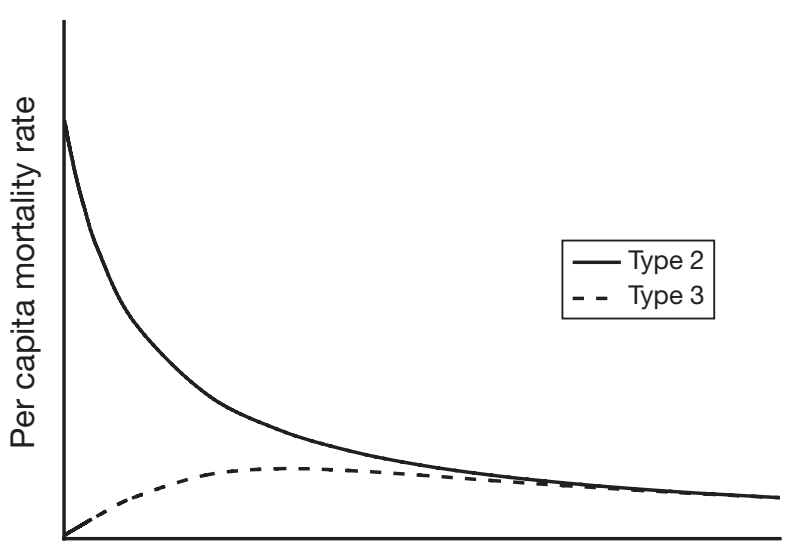

Abundance

Fig. 1. Type 2 and Type 3 functional response curves (left) and resulting per-capita mortality rates for prey (right)

predators are observed repeatedly under different regimes of prey availability (Real 1979). The minke whale study had to be conducted in this way: the Norwegian whale fishery operates only during a restricted period, and stomach sampling is presently the only feasible method for estimating consumption rates for these animals directly. We therefore assume that the functional response of the minke whales is constant throughout their period of foraging in the Barents Sea, and that the whales sampled during the study provide a representative random sample of the population.

Resource abundance was assessed, parallel to the sampling of whales, by 2 research vessels running standard acoustic surveys. These surveys were carried out close to the location of whale captures and within a short time of those captures, in order to obtain the best possible estimates of prey abundance that would have been experienced by the whales while foraging.

When deciding on the form of our functional response model, it was important to consider the restricted size of our data set, and to limit the number of parameters to be estimated, while applying a model that would be able to capture the important features of predation behaviour that might influence the population trajectories of predators and prey. A priori, it seems probable that baleen whales experience changes in foraging efficiency as the abundance of prey changes, and studies on other marine mammals show that they appear to optimise energy intake by making small-scale foraging decisions that result in non-linear functional responses (Mori \& Boyd 2004). Empirical evidence also suggests that a Type 3 functional response might be expected; a Type 3 functional response emerged from fitting a consumption model in a recent large-scale study in which minke whale predation on herring was assessed (Tjelmeland \& Lindstrøm 2005). A previous analysis of the results of the localised foraging studies examined in the present study used Chesson's Index to examine prey preferences, and these were found to change with prey availability. This is consistent with a Type 3 but not with a Type 2 functional response. Therefore, we chose to fit a flexible model with a variable shape parameter $m$, so that the model could take either Type 2 or Type 3 forms.

MSFR models are sometimes fitted as sub-models within larger dynamical models that include predatorprey interactions (Koen Alonso \& Yodzis 2005, Yodzis 2000). Functional-response equations may also be fitted directly to consumption-rate and preyavailability data, and these data may come from laboratory experiments or from field observations as in the present study (Rindorf \& Gislason 2005). Most such studies are of single-prey systems, or multispecies systems in which the interaction between a generalist and 1 focal prey is modelled as though it was a singlespecies interaction (Redpath \& Thirgood 1999). Such models are often fitted using non-linear least squares approaches, sometimes with a prior log-transformation of the data such that it conforms better to the assumption that errors are normally distributed (Rindorf \& Gislason 2005). Trexler et al. (1988) pointed out some of the difficulties of distinguishing the true shape of a functional response by fitting to data, and Juliano (2001) suggested that it is useful to include an intermediate 'logistic regression' step in order to investigate the curvature of the functional response curve. However, MSFR models remain particularly difficult to fit because of the need for a large quantity of data to cover a full range of prey abundances and combinations of these.

In practice, such a comprehensive data set is often difficult to obtain, especially for field situations where it is necessary to use what prey abundances occur 
naturally, which cannot be set by an experimenter. Here we adopted a Bayesian approach, which allows the use of prior probability distributions of each parameter, thereby restricting the area of parameter space that is searched during the fitting process. This can to some extent overcome the problem of sparse data, given that suitable priors are available. These may come either from independent experiments and measurements, by reasoning from first principles, or from expert opinion. Subsequent inference can be based on the full joint distribution of parameters that results from the Bayesian fitting process, enabling an exploration both of the predictions of the model, and the uncertainty in these predictions. The use of Bayesian methods to estimate the parameters of an MSFR model is relatively new (Asseburg et al. 2004) and, as far as we know, no studies of multispecies responses of cetacean predators have been published previously.

\section{MATERIALS AND METHODS}

Whale and resource sampling. The 26 minke whales ( 2 males and 24 females) included in this study were collected during commercial whaling operations conducted between May and June 1998 in 3 smallscale areas (Fig. 2). The whales were killed during the Norwegian commercial whaling for minke whales, which is legal according to Norwegian national legislation and regulations, and according to international

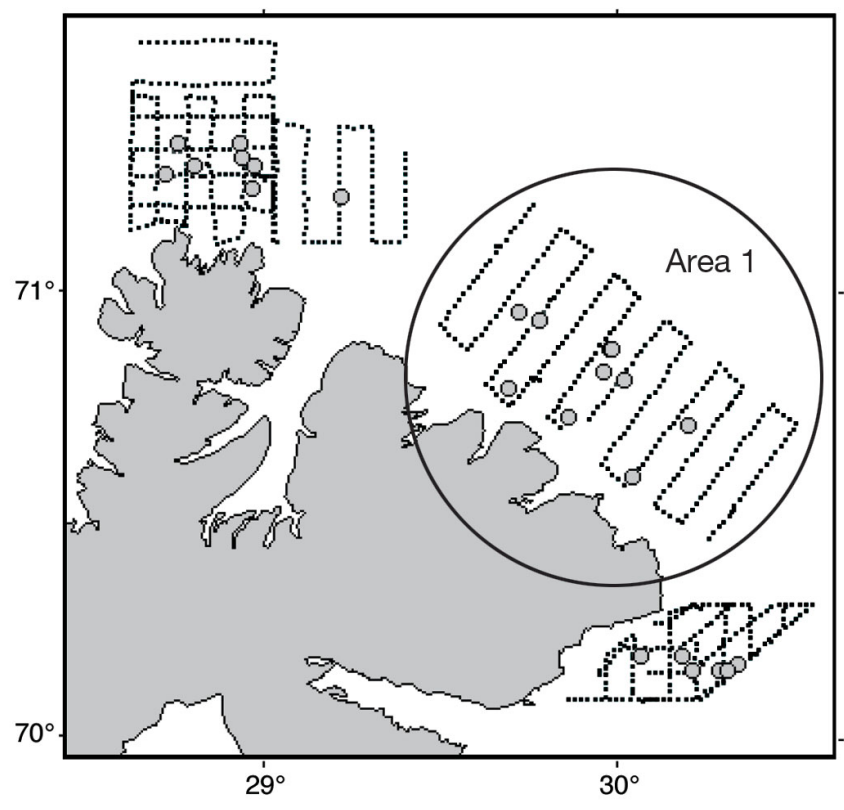

Fig. 2. Catch positions of 30 minke whales (grey circles) sampled in the southern Barents Sea between May and June in 1998 and 1999. Track lines of resource surveys represented by small black dots at $1 \mathrm{n}$ mile intervals, the spatial scale over which mean prey densities were measured conventions to which Norway is a party. The whales were killed according to whaling procedures described by Haug et al. (1996), and immediately taken onboard the vessel for dissection and biological sampling. The stomach contents were treated according to standard procedures. Fish and invertebrates were identified to species, and the biomass of each species in a given stomach sample was then recorded (see Haug et al. 1995).

In the laboratory, fish specimens were divided into 4 digestion states as defined by Lindstrøm et al. (1998). In order to reduce some of the main sources of uncertainty in the reconstruction of stomach contents, such as differential passage and degradation rates of different fish types and sizes (Bigg \& Fawcett 1985) and accumulation of hard remains such as otoliths, only undigested and moderately digested fish prey were included in the analysis, thereby reducing the uncertainty of the actual foraging locations of the whales.

The 3 most important prey species (herring, capelin and krill) were included in the analysis. Minke whales are also known to exploit gadoids (mainly cod, haddock and saithe) in the Barents Sea, but gadoids were almost absent in the whale diets in this localised study, and therefore excluded from the analysis. No attempt was made to classify prey into size classes because minke whales do not appear to be selective for prey size (Haug et al. 2002).

In areas where whales were caught, the prey biomass was assessed within $2 \mathrm{~d}$ of the time of whale capture using standard acoustic survey procedures (Fig. 2). Thus, the spatial distribution and the timing of the survey areas was constrained by the distribution and timing of whale sampling. Continuous acoustic recordings of fish and euphausiids were made by a calibrated echo integration unit consisting of a 38 and $120 \mathrm{kHz}$ Simrad EK-500 splitbeam echosounding system (Bodholt et al. 1989) connected to a BEI post processing system (Foote et al. 1991). A minimum acoustic threshold of $-88 \mathrm{~dB} \mathrm{~Sv}$ was applied to detect euphausiids.

The allocation of acoustic values $\left(S_{\mathrm{A}}\right.$, area backscattering coefficient) was determined on the basis of the acoustic character of species and trawl samples. Both pelagic and demersal trawling were performed in response to potential changes in the echo sounder registrations. For pelagic trawling, a 14 fathom trawl (Harstad) fitted with a Scanmar depth recorder was used, while a 'Super Campelin' 1800 mesh shrimp trawl was used for demersal trawling. Both trawls were fitted with an $8 \mathrm{~mm}$ net inside the cod-end, thereby making it possible to sample fish juveniles and euphausiids. Pelagic and demersal trawling was standardised to 30 and 20 min duration, respectively, and the trawling speed was approximately 3 knots. 
The recorded $S_{\mathrm{A}}$-value, averaged over 1 square nautical mile (n mile ${ }^{2}$ ) was converted to biomass ( $\rho$ ) according to the relation:

$$
\rho=\frac{S_{\mathrm{A}}}{4 \pi \times 10^{0.1 \times \overline{\mathrm{TS}}}}
$$

where TS is the mean target strength of scattering organisms, which varies between species and body length (MacLennan \& Simmonds 1992). The effect of vertical variations in the distribution of prey was not considered: only prey within the top $100 \mathrm{~m}$ of the water column was considered in the analysis because minke whales mainly forage in surface waters.

Spatial modelling and numerical sampling of prey densities. The precise foraging locations of the whales prior to capture were unknown. Because our consumption estimates are based only on undigested and/or moderately digested fish prey, we assumed that these prey were ingested in the previous $2 \mathrm{~h}$. Given that a minke whale can potentially travel $5 \mathrm{n}$ miles $\mathrm{h}^{-1}$, and that the abundance of pelagic prey may vary considerably in time and space (Harbitz \& Lindstrøm 2001, Lindstrøm \& Haug 2001), there is considerable uncertainty in the prey abundance that a whale may have experienced while foraging. In order to obtain estimates of prey abundance for the whales, it was therefore necessary to model the whales' foraging movements and to take these into account when assessing the availability of prey to the whales.

Because very little is known about small-scale foraging movements of these animals, the following assumptions were made (J. Matthiopoulos pers. comm.).

(1) The distribution of whale locations prior to capture, assuming that a whale is a randomly-moving animal, can be described using a Gaussian kernel (Turchin 1998):

$$
\mathrm{p}(s)=\frac{1}{2 \pi \sigma^{2}} \mathrm{e}^{\frac{-s^{2}}{2 \sigma^{2}}}
$$

where $s$ is the distance from the centre of the distribution and the width of the kernel $\sigma$ corresponds to the maximum likely distance travelled by a whale during a $2 \mathrm{~h}$ period.

(2) Fresh and moderately digested food in the whale stomachs was derived from 1 discrete foraging event

(3) Food present in the stomach was consumed within the $2 \mathrm{~h}$ prior to capture.

The prey availability experienced by the whales was estimated by sampling from the spatial distribution of prey around the sites of whale capture, according to the Gaussian kernel.

Most whales were caught between the prey survey transects. In order to sample prey biomass data over the whole area of the Gaussian kernel, the prey bio- mass data were interpolated. We chose to do this by fitting generalised additive models (GAMs) to the data using the 'mgcv' package in R (Wood 2000) so that an appropriate model for the stochasticity in measurements of prey density could be applied.

In GAMs, a response variable $\mu$ is modelled as a function of predictor variables, with a 'link function' summarising the relationship:

$$
g(\mu)=s(x, y)
$$

where $\mu$ is a vector of the expected values of observations, $\boldsymbol{x}$ and $y$ are vectors of Cartesian co-ordinates calculated on a $1 \mathrm{n}$ mile ${ }^{2}$ grid from latitude and longitude co-ordinates, and $S$ is a smoothed function of $x$ and $y$. Smoothing is carried out using generalised cross-validation to select the value of the smoothing parameter. Variable $g$ represents the link function - a square root link function was used in this case, and $\mu$ is the expected value of prey abundance a measured in the acoustic survey. Prey occurs as aggregations of discrete individuals, and stochasticity in prey measurements was modelled using an over-dispersed Poisson error distribution in which a scale factor is introduced to allow the variance of the distribution to take values larger than the mean.

Using the GAM models, the prey distributions were predicted over a surface of $1 \mathrm{n}$ mile ${ }^{2}$ grids within the $x-y$ limits of the area defined by the distribution of prey data. To avoid unjustified extrapolations, the prey densities outside this area were set to a uniform value equal to the mean value inside the prediction area. Prey biomass estimates were then sampled from this 2-dimensional prey abundance surface according to the kernel representing random whale movements. However, before the sampling could be carried out, it was necessary to estimate the size of the movement kernel for the whales.

The available data on minke whale movement patterns is mainly based upon boat observations. It is known for example that minkes will return repeatedly to favoured foraging areas in Canada, and that they may remain in such areas for some time (Piatt \& Methven 1992). However, details of movement within the foraging area such as average speed and range are not well known. Minke whales have been observed to travel at high speeds of up to $20 \mathrm{n}$ miles per hour for short periods, but it is unlikely that they sustain such speeds while foraging.

Telemetry data from 5 minke whales tagged with satellite-linked radio transmitters in the northeast Atlantic in 1995 (E. Nordøy, L. M. Folkow, A. S. Blix unpubl. data) were used to parameterise the movement kernel. One whale was tracked successfully over a $31 \mathrm{~d}$ period, giving on average 1.58 uplinks per day. Evidently, these data are not sufficiently detailed to 
give a true picture of minke whale foraging movements. However, by assuming that movement could be modelled as a random walk process, and using those parts of the tracks that, according to the authors (E. Nordøy, L. M. Folkow, A. S. Blix unpubl. data), represent foraging periods, the width of the Gaussian kernel representing whale movements was estimated using the following diffusion equation:

$$
\sigma^{2}=D t
$$

where $\sigma$ represents the width or SD of the Gaussian kernel in $\mathrm{n}$ miles, $D$ is the diffusion coefficient (n miles ${ }^{2}$ $\mathrm{h}^{-1}$ ) and $t$ is time (h) (Turchin 1998). The diameter of the foraging area could then be re-scaled from a $10 \mathrm{~d}$ period to a $2 \mathrm{~h}$ period.

Based on the tagging experiment (E. Nordøy, L. M. Folkow, A. S. Blix unpubl. data) in which the area used by a foraging whale during a $10 \mathrm{~d}$ period had a diameter of $80 \mathrm{n}$ miles, we assumed that this distance represented $4 \sigma$. The value of $\sigma$ for a $2 \mathrm{~h}$ interval was then given by $\sigma=1.83 \mathrm{n}$ miles.

The 2-dimensional space around the point of each whale capture was sampled as follows. For each sample point, a vector $\boldsymbol{d}$ was chosen, with the length of $\boldsymbol{d}$ chosen at random from a Gaussian kernel:

$$
\boldsymbol{d} \sim N(0, \sigma)
$$

and the direction $\theta$ (in ${ }^{\circ}$ from due North) chosen according to a uniform distribution:

$$
\theta \sim U(0,360)
$$

Three estimates of prey biomass ( 1 for each prey type) were generated from the corresponding GAMs for the sample point, thus capturing the spatial correlations between prey types. By repeating the whale sampling procedure 1000 times for each whale capture, a $1000 \times$ 3 prey biomass matrix was constructed for each whale.

The functional response model. Minke whales are known as generalist predators that readily adapt to local prey abundance situations (e.g. Haug et al. 2002). Predation behaviour is modelled using a modified version of the functional response (FR) model described by Real (1977). The model was written for multiple prey species, and re-parameterised in terms of maximum consumption and half-satiation prey availability:

$$
C_{i}=\operatorname{cmax}_{i} \frac{\left(\frac{N_{i}}{\text { Nhalf }_{i}}\right)^{m_{i}}}{1+\sum_{j=1}^{k}\left(\frac{N_{j}}{\text { Nhalf }_{j}}\right)^{m_{j}}}
$$

where $C_{i}$ and $\operatorname{cmax}_{i}$ are the consumption rate and maximum consumption rate of prey $i\left(\mathrm{~kg} \mathrm{~h}^{-1}\right)$, respectively, $N_{i}$ is abundance of prey $i$ (tonnes n mile ${ }^{-2}$ ), Nhalf $f_{i}$ is the half-saturation constant (that value of prey abundance for which consumption is half its maximal value), $m_{i}$ is the parameter that sets the shape of the FR $\left(m_{i}=1\right.$ corresponds to a Type II FR for prey species $i$, whereas $m_{\mathrm{i}}>1$ corresponds to a Type III FR).

The assumption that all whales in the study belong to a single population and that there is no difference between demographic classes was made owing to limited data and lack of scientific evidence (Haug et al. 1995).

Model fitting and choice of parameter priors. The model fitting was implemented using Markov Chain Monte Carlo (MCMC) sampling, where parameter space is searched at random and sets of parameters are accepted or rejected in order to maximise the probability:

$$
\mathrm{P}(\theta \mid y) \propto \mathrm{P}(y \mid \theta) \mathrm{p}(\theta)
$$

The probability of a set of parameters $\theta$ given the data $y$ is proportional to the likelihood term $\mathrm{P}(y \mid \theta)$ multiplied by the prior distribution of the parameters $\mathrm{P}(\theta)$.

If run for long enough, the MCMC produces a representative sample from the joint posterior distribution of parameters (Hilborn \& Mangel 1997).

MCMC was implemented in WinBugs (Gelman et al. 1995) using the slice-sampling algorithm of Neal (1997), which improves the efficiency of the parameter search.

The prior distribution of $\mathrm{cmax}$, the maximum consumption rate of a given prey species, was estimated based on bootstrap resampling of stomach content data from a time series (1992 to 2003). With shape parameter given first and rate parameter second for each prey species, these priors were:

$$
\begin{aligned}
& C \max _{1} \sim \Gamma(31,0.3) \\
& C \max _{2} \sim \Gamma(15,0.3) \\
& C \max _{3} \sim \Gamma(30.0 .5)
\end{aligned}
$$

Gamma distributed priors for $m$ were based on parameter distributions obtained from a more recent large scale study where minke whale predation on Norwegian spring-spawning herring was assessed (Tjelmeland \& Lindstrøm 2005). These priors allowed for a wide range of possible shapes for each singlespecies functional response, and for different forms of switching that might occur between prey types:

$$
\begin{aligned}
& m_{1} \sim \Gamma(76,20) \\
& m_{1} \sim \Gamma(19,10) \\
& m_{1} \sim \Gamma(35,11)
\end{aligned}
$$

There were no data available to inform priors in Nhalf. Thus, broad priors were set to include the full range of possible prey availabilities:

$$
\begin{aligned}
& \text { Nhalf }_{1} \sim \Gamma(3,0.0001) \\
& \text { Nhalf }_{2} \sim \Gamma(3,0.00005) \\
& \text { Nhalf }_{3} \sim \Gamma(3,0.00005)
\end{aligned}
$$

The observations of fresh biomass from stomach samples represented 2-hourly consumption rates. The 
1000 replicate samples of prey abundance for each species were treated as duplicate data points and matched to the corresponding consumption rate of each whale.

Error model for stomach data. Because minke whales and other baleen whales feed on discrete prey patches and the foraging event in this study was very short (ca. $2 \mathrm{~h}$ ), there is likely to be considerable stochastic variation in consumption. The distribution of the different prey biomasses in the stomach of the whales generally monotonically decreases with a heavy tail to the right and a large number of zeros. A zero-inflated Poisson distribution (Martin et al. 2005) was used to model the error distribution in which a 'probability parameter' $p$ was introduced to represent the probability that prey had been consumed in the period prior to capture, and to allow for the possibility that no prey was consumed. This parameter was also estimated during the model-fitting process:

$$
c_{i}=\left\{\begin{array}{l}
0, \operatorname{Pr}(1-p) \\
\operatorname{Po}\left(\lambda_{i}\right), \operatorname{Pr}(p)
\end{array}\right.
$$

where $P_{o}$ represents the Poisson distribution and $\lambda$ represents the expected quantity of food in a stomach, given that some food is present.

Fitting the model. The MSFR model was coded in the WinBugs programming language and implemented using the slice-sampling algorithm according to Neal (1997). Two parallel chains were run to check for convergence. The posterior parameter distributions were examined by plotting histograms of parameter based on 1000 draws from the Markov chain. Prey availability ( $N$ in Eq. 10) was estimated using resampling based on a whale-movement kernel of $1.83 \mathrm{n}$ miles, as described above.

This process was then repeated. Firstly, to test for sensitivity to the prior on $\mathrm{m}$. Uninformative uniform priors for $m$ were applied in order to test for sensitivity to the prior assumptions about this parameter. The uniform prior allowed $m$ to take values of between 1 and 10 . This was the only parameter for which prior sensitivity was examined: priors on Nhalf were uninformative in any case, and the priors on $\operatorname{cmax}$ were considered to be reliably estimated from the large stomach database. Parameter $\theta$ was set at $1.83 \mathrm{n}$ miles, firstly with the original gamma priors on $m, c$ max and Nhalf, but with data based on sampling using a range of foraging kernels from 0.5 to $5.0 \mathrm{n}$ miles. It was not feasible to explore the effects of substantially larger foraging kernels, because then the spatial sampling would fall substantially outside the area for which prey distributions could be mapped and the procedure would not be informative. We also suggest that smaller foraging kernels are more probable than larger ones a point we return to in the 'Discussion'.
Simulations. In order to explore how minke whales may affect local prey aggregations, we performed 3 simulations of prey consumption, 1 for each prey species. The prey was assumed to be stationary in space during the simulation, i.e. no migration of prey in or out of the simulation area $\left(1 \mathrm{n}\right.$ mile $\left.{ }^{2}\right)$. The simulation was terminated after $24 \mathrm{~d}$.

In the first simulation, the starting values of the prey abundances were set so that capelin availability was initially high while that of krill and herring was low. In contrast, in the second and third simulations, the initial availability of herring and krill was high while availability of other prey was low.

\section{RESULTS}

\section{Spatial sampling}

Fig. 3 shows the spatial sampling procedure in Area 1 ; a bi-normal distribution of 1000 potential whale feeding locations around each catch position is clearly illustrated. The spatial sampling procedure, yielding 1000 potential prey abundance values for each whale, resulted in a statistical distribution of prey biomass available to each individual whale. The mean of this distribution is assumed to represent the best prey biomass estimate, whereas the width of the distribution represents the uncertainty of this value.

The prey biomass estimates suggest considerable heterogeneity in prey abundance between the locations of whale captures (Table 1). Herring appears to be the most clustered prey, with mean biomass estimates for each whale varying from 0 to $13677 \mathrm{~kg}$ $\mathrm{n}$ mile ${ }^{-2}$, followed by capelin (337 to $11533 \mathrm{~kg} \mathrm{n} \mathrm{mile}{ }^{-2}$ ) and krill (5835 to $39376 \mathrm{~kg} \mathrm{n} \mathrm{mile}{ }^{-2}$ ).

The distributions of prey biomass for individual whales were skewed. The degree of skewness depended on the spatial distribution of prey relative to the whale, and whether this prey was evenly distributed in space or very clustered. The SD illustrates the potential fine-scale variation in prey biomass that an individual whale may experience. The fine scale variation in herring biomass $(0$ to $5811 \mathrm{~kg} \mathrm{n} \mathrm{mile}{ }^{-2}$ ) varied most profoundly, followed by krill (2164 to $10650 \mathrm{~kg} \mathrm{n} \mathrm{mile}{ }^{-2}$ ) and capelin (251 to $3334 \mathrm{~kg} \mathrm{n} \mathrm{mile}{ }^{-2}$ ).

\section{The $1.83 \mathrm{n}$ mile movement kernel, MCMC results and implications}

Where the availability data was sampled using the 'best estimate' kernel of $1.83 \mathrm{n}$ miles, the MCMC converged satisfactorily after 100000 iterations. Con- 


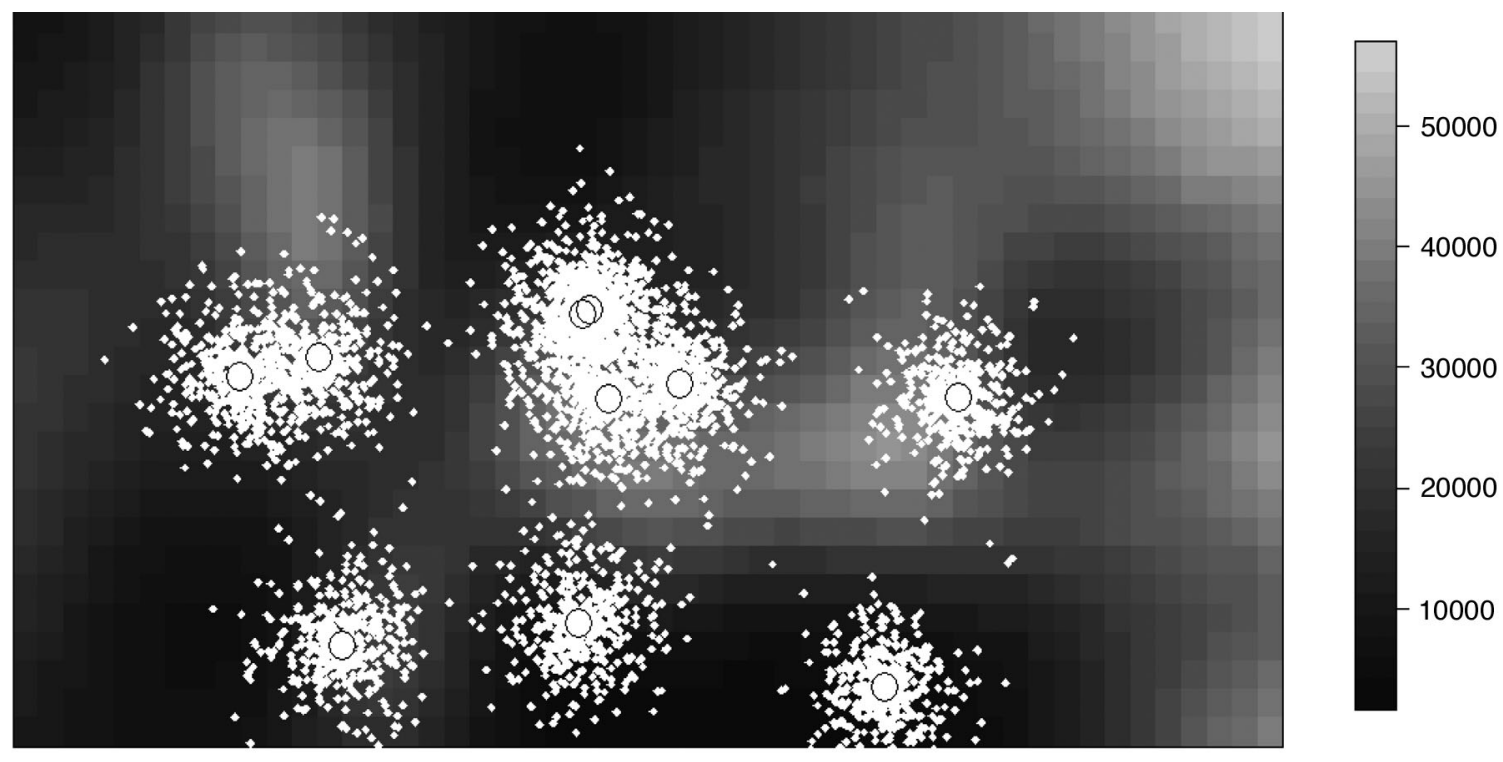

Fig. 3. Density of krill ( $\mathrm{kg} \mathrm{n} \mathrm{mile}{ }^{-2}$ ) plotted on a $1 \mathrm{n}$ mile grid in Area 1 (see Fig. 2), along with catch positions of minke whales (circles) and 1000 potential foraging locations sampled from the Gaussian kernel (small white dots)

vergence was checked by running 2 Markov chains, examining the chains by eye to check that good mixing had taken place, and using the statistic $\hat{R}$. $\hat{R}$ is calculated based on the variance within and between chains, and tends to 1 if the chains are long enough to adequately explore the distribution of parameters (Gelman et al. 1995). The histograms and the grey lines in Fig. 4 show (respectively) the estimated marginal posterior and prior probability distributions of the model parameters $(m, c m a x$ and Nhalf $)$ for each prey species, given the assumed movement kernel of $1.83 \mathrm{n}$ miles. The posterior distributions appeared well defined and different to the prior distributions in all cases, indicating that the data had contributed information to refine the prior distribution.

The means and SD of the marginal posterior distribution are given in Table 2. The parameter estimates varied considerably among prey species. All prey switching coefficients were significantly greater than 1, i.e. the posterior distributions did not overlap 1, suggesting that minke whales display a Type III functional response to all their major prey. However, it must be noted that the marginal posterior distributions illustrated for this movement kernel in Fig. 4 need to be interpreted with some caution because the posterior distribution should be properly viewed as a joint distribution of all these parameters.

The plots in Fig. 5 were constructed based on the parameter estimates for the MSFR, assuming that the abundance of prey in the area where the whale was foraging was precisely known. This figure shows that the consumption rate of fish prey is very sensitive to the abundance of alternative prey, but that the consumption rate of krill appears to be less sensitive to the presence of other prey in the system.

Fig. 6 shows the results from the prey consumption simulation. A randomly chosen whale is preying on spatially stationary prey. Given the starting values of the prey biomasses, the whale hardly affects the biomass of herring and krill (mid and lower panels), whereas the biomass of capelin declined substantially from 11533 to $2268 \mathrm{~kg}$ in $10 \mathrm{~d}$.

\section{Sensitivity testing: shape parameter $\mathbf{m}$}

The results of running the MCMC with a uniform prior on $m$ are compared with the above results in Table 2. Parameter estimates are similar for uniform or $\Gamma$ priors, with substantial overlap between the marginal parameter distributions for each parameter. Therefore, we suggest that model-fitting is not very sensitive to prior assumptions about $m$, and that the inferred values of $m$ are mainly informed by the data.

\section{Sensitivity testing: movement kernel $\theta$}

The estimated values of the MSFR parameters were sensitive to the value of this parameter. At high values of $\theta, m$ tended to be close to 1 . This is illustrated in Fig. 7. This result is perhaps not surprising, given that the value of $\theta$ influenced both the mean and SD of the prey abundance $(N)$ available to each whale, and 
would also be expected to change the relative quantities of the 3 prey available to each whale. In general, larger $\theta$ gave rise to wider distributions for each value of $N$ (i.e. increasing the SD), making it more 'difficult' for the MCMC to fit the model (more iterations were required for convergence). Because the spatial sampling of prey densities produced different 'data sets' for each of the movement kernels that we applied, it was not possible to use conventional measures of model fit to choose what the appropriate kernel was.

\section{DISCUSSION}

The purpose of this study was to estimate the smallscale functional response of northeast Atlantic minke whales with respect to their most important prey species.

The results are based upon 4 major assumptions: (1) minke whales consume capelin, herring and krill almost exclusively; if other prey can form a significant part of the diet, then these are virtually absent from the study area, (2) the whales in this study are an unbiased random sample from the population of interest, implying that a general MSFR model can be estimated,
(3) the stomach contents of each whale represent a single foraging event in 1 location, and (4) the whale locations prior to capture can be correctly represented by a Gaussian kernel, and the width of this kernel can be estimated correctly.

Capelin, herring and krill are the most important prey of minke whales in the Barents Sea; however, consumption of gadoid fish (cod, haddock and saithe) may also be significant, particularly in years when the abundance of herring and capelin is low (Haug et al. 2002). Ignoring a prey species when fitting an MSFR may be justified if the abundance of that prey can be considered to be very small, or constant over time and space, or if consumption rates of the prey in question are always low (i.e. the predator has a strong preference for alternative prey). Gadoid fish were excluded from the analysis owing to their low dietary importance. Thus, Assumption 1 is only valid for this localised study. An increased importance of gadoids is likely to reduce the consumption rate of capelin, herring and krill. This reduces the generality of the MSFR we have derived, making it difficult to apply for the entire Barents Sea population of minke whales.

The second assumption implies that individual whales do not specialize, and that there is no signifi-

Table 1. Estimated biomass ( $\mathrm{kg} \mathrm{n}$ mile ${ }^{-2}$ ) of capelin, herring and krill in the Barents Sea, and in 26 minke whale forestomachs $(\mathrm{kg})$. Estimated prey abundance available to whales given as mean \pm SD of 1000 resource samples based on the $1.8 \mathrm{n}$ mile movement kernel

\begin{tabular}{|c|c|c|c|c|c|c|}
\hline \multirow{2}{*}{ Whale } & \multicolumn{3}{|c|}{ - Barents Sea } & \multirow{2}{*}{ Capelin } & \multicolumn{2}{|c|}{ Thale stomachs } \\
\hline & Capelin & Herring & Krill & & Herring & Krill \\
\hline 1 & $4200 \pm 1483$ & $7530 \pm 5166$ & $39376 \pm 7491$ & 0.00 & 0.00 & 1.55 \\
\hline 2 & $6281 \pm 1351$ & $4099 \pm 2910$ & $30010 \pm 7627$ & 0.00 & 0.00 & 5.32 \\
\hline 3 & $4349 \pm 775$ & $1696 \pm 700$ & $33705 \pm 4781$ & 0.00 & 0.00 & 9.60 \\
\hline 4 & $3231 \pm 822$ & $863 \pm 509$ & $27086 \pm 5503$ & 0.00 & 0.00 & 17.53 \\
\hline 5 & $3275 \pm 865$ & $826 \pm 570$ & $26486 \pm 5457$ & 0.00 & 0.00 & 9.27 \\
\hline 6 & $337 \pm 771$ & $9777 \pm 5055$ & $13596 \pm 7976$ & 0.00 & 0.29 & 6.83 \\
\hline 7 & $2868 \pm 677$ & $13677 \pm 5811$ & $13868 \pm 6455$ & 0.41 & 4.43 & 0.00 \\
\hline 8 & $2192 \pm 857$ & $1341 \pm 587$ & $23795 \pm 10041$ & 1.76 & 0.00 & 1.30 \\
\hline 9 & $2166 \pm 844$ & $1287 \pm 532$ & $23725 \pm 9767$ & 3.96 & 0.00 & 5.00 \\
\hline 10 & $733 \pm 672$ & $1256 \pm 781$ & $30483 \pm 10650$ & 0.00 & 0.00 & 15.09 \\
\hline 11 & $5696 \pm 1863$ & $132 \pm 1379$ & $16379 \pm 5825$ & 10.56 & 0.00 & 19.53 \\
\hline 12 & $11058 \pm 2595$ & $26 \pm 151$ & $16006 \pm 2416$ & 7.84 & 0.00 & 0.20 \\
\hline 13 & $8545 \pm 3119$ & $7 \pm 11$ & $20299 \pm 4691$ & 10.21 & 0.00 & 0.00 \\
\hline 14 & $11439 \pm 2843$ & $321 \pm 49$ & $20242 \pm 3851$ & 0.00 & 0.00 & 0.00 \\
\hline 15 & $11533 \pm 2827$ & $351 \pm 48$ & $20239 \pm 4070$ & 0.00 & 0.00 & 0.00 \\
\hline 16 & $6137 \pm 2238$ & $0 \pm 0$ & $22975 \pm 4156$ & 0.00 & 0.00 & 0.00 \\
\hline 17 & $1650 \pm 251$ & $1 \pm 5$ & $23151 \pm 4026$ & 0.00 & 0.00 & 56.24 \\
\hline 18 & $1350 \pm 286$ & $0 \pm 0$ & $16020 \pm 4017$ & 0.00 & 0.00 & 42.20 \\
\hline 19 & $1276 \pm 566$ & $3401 \pm 4005$ & $5835 \pm 5019$ & 0.00 & 0.00 & 2.15 \\
\hline 20 & $3159 \pm 752$ & $54 \pm 799$ & $6020 \pm 5253$ & 19.19 & 0.00 & 0.00 \\
\hline 21 & $11119 \pm 3307$ & $315 \pm 590$ & $12686 \pm 2164$ & 0.00 & 0.00 & 57.66 \\
\hline 22 & $6991 \pm 3334$ & $310 \pm 540$ & $20548 \pm 9287$ & 0.00 & 0.00 & 0.99 \\
\hline 23 & $4111 \pm 691$ & $72 \pm 248$ & $12703 \pm 3877$ & 30.62 & 0.00 & 6.96 \\
\hline 24 & $5293 \pm 1423$ & $13 \pm 32$ & $27155 \pm 8401$ & 0.00 & 0.00 & 0.00 \\
\hline 25 & $2118 \pm 484$ & $5228 \pm 3300$ & $10269 \pm 5085$ & 0.00 & 1.13 & 24.19 \\
\hline 26 & $2263 \pm 604$ & $8254 \pm 4580$ & $8901 \pm 5929$ & 0.00 & 9.15 & 0.00 \\
\hline
\end{tabular}



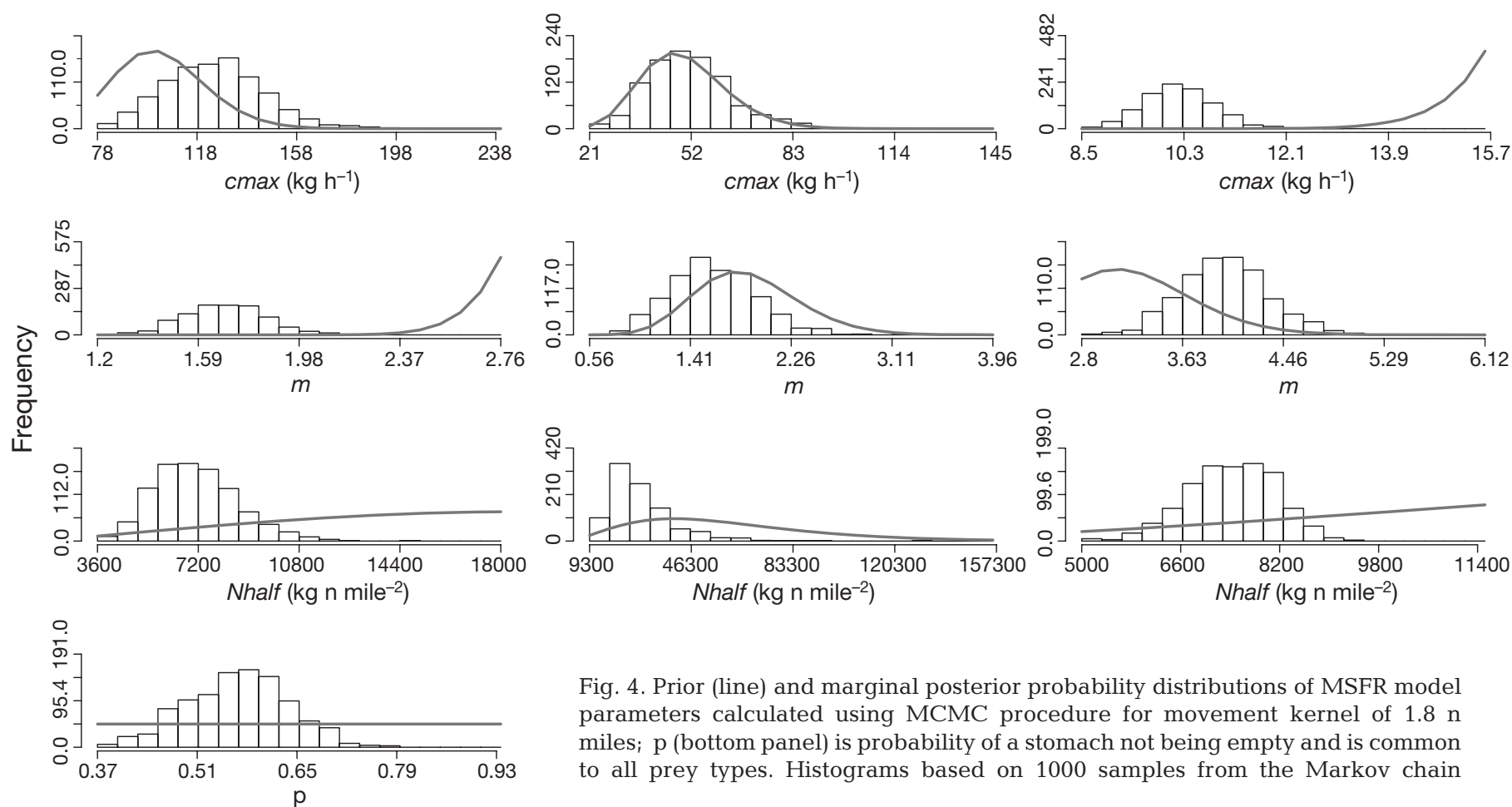

Fig. 4. Prior (line) and marginal posterior probability distributions of MSFR model parameters calculated using MCMC procedure for movement kernel of $1.8 \mathrm{n}$ miles; p (bottom panel) is probability of a stomach not being empty and is common to all prey types. Histograms based on 1000 samples from the Markov chain

cant difference in prey preference or consumption rate among different size/sex classes of whales. However, individual minke whales may display specialised feeding strategies: they can either pursue concentrated prey resources, or concentrate the prey by active pursuit and herding, or both (Hoelzel et al. 1989). Both strategies pursue patchy resources within predictable areas. Because the fine-scale foraging behaviour of the whales was not observed in this study, we cannot confirm or dismiss whether minke whales used different foraging strategies in the 3 subareas. Further, the diet composition may be biased towards capelin owing to a dominance of females in the sample: females appear to prefer capelin and saithe, whereas males appear to prefer herring (Haug et al. 2002). Fitting separate FR models for different individuals or a subset of the population (e.g. selected by area, age and sex) would reduce this uncertainty if sufficient data for each subset of whales were available. Given the present data set, it was also not possible to determine whether the functional response of whales varies over the foraging season in the Barents Sea.

Assumption 3 is difficult to validate conclusively, but is supported by several arguments. One is that the time frame of foraging represented by the stomach samples is short, owing to the use of only fresh or partially digested prey, making it more likely that the stomach contents represent a single foraging event. Secondly, field observations from studies in other areas indicate that minke whales are often spatially stationary during feeding events (Simrad et al. 2002). More detailed studies of foraging behaviour in Barents Sea minke whales would clearly be of great interest in order to determine whether this assumption is reasonable for the animals in this study. Third, the modelling of prey abundance surfaces tends to smooth out local variations in prey abundance, making it more likely that sampled prey abundances were representative of food availability to foraging whales, even if those whales

Table 2. Comparison among parameter estimates for the MSFR when priors on $m$ are set using estimates from the previous whole-Barents Sea modelling exercise with independent data ( $\Gamma$ prior), and when priors on $m$ are uninformative (uniform); c: capelin; h: herring; k: krill

\begin{tabular}{|lcccc|}
\hline \multirow{2}{*}{ Parameter } & \multicolumn{2}{c}{$\Gamma$ prior } & \multicolumn{2}{c}{ Uniform prior } \\
& Mean & SD & Mean & SD \\
\hline Nhalf(c) & 7127 & 1490 & 10500 & 3502 \\
Nhalf(h) & 27930 & 12200 & 32300 & 14800 \\
Nhalf $(\mathrm{k})$ & 7427 & 710 & 8000 & 703 \\
$\operatorname{cmax}(\mathrm{c})$ & 125 & 19.5 & 122 & 18.6 \\
$\operatorname{cmax}(\mathrm{h})$ & 52 & 12.7 & 49.9 & 12.9 \\
$\operatorname{cmax}(\mathrm{k})$ & 10 & 0.617 & 10.4 & 0.612 \\
$\operatorname{m}(\mathrm{c})$ & 1.69 & 0.156 & 1.06 & 0.0616 \\
$\operatorname{m}(\mathrm{h})$ & 1.61 & 0.361 & 1.57 & 0.512 \\
$\operatorname{m}(\mathrm{k})$ & 3.98 & 0.356 & 3.95 & 0.375 \\
$\mathrm{p}$ & 0.567 & 0.0704 & 0.540 & 0.0684 \\
\hline
\end{tabular}



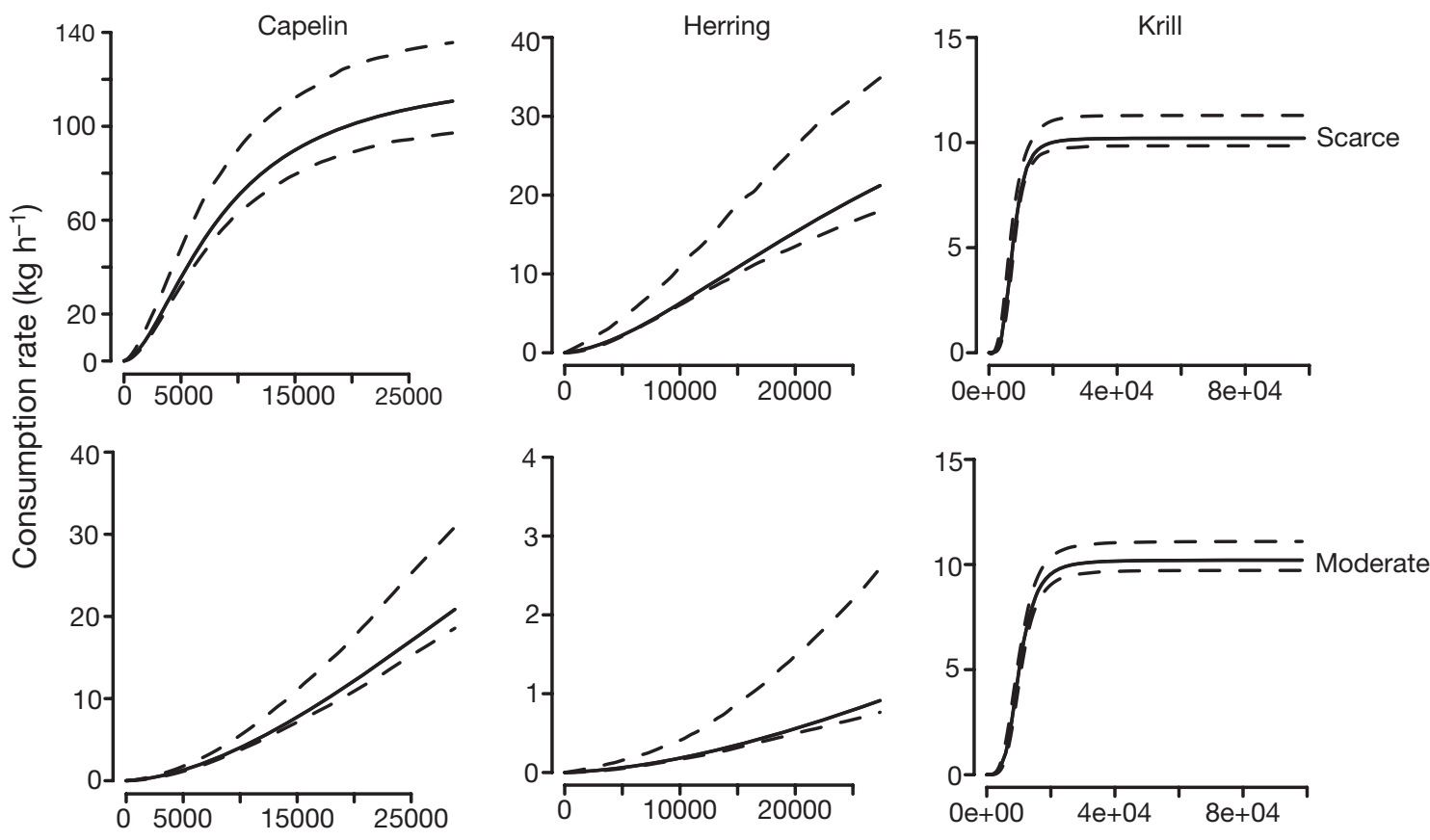

Prey abundance ( $\mathrm{kg} \mathrm{n}$ mile-2)

Fig. 5. Predicted functional response of capelin, herring and krill. Confidence intervals (95\% CI) determined from random sampling of parameters from the Markov chain. Consumption estimates calculated for each prey species with the biomass of all other prey fixed at moderate or low abundance. Moderate: alternative prey occurs with moderate biomass (top row); Scarce: alternative prey is scarce (bottom row). All prey availabilities are within the range of the data set

did make small movements and undertook several different foraging bouts within a limited area.

Hoelzel et al. (1989) suggest that minke whales forage randomly on a small scale, consistent with our assumption of a Guassian kernel for whale locations and the computer sampling method we adopted for estimating prey availability (Assumption 4). We believe that, at present, the telemetry study by $\mathrm{E}$. Nordøy, L. M. Folkow, A. S. Blix (unpubl. data) gives the best possible estimate for the width of the movement kernel for northeast Atlantic minke whales in the Barents Sea, but these observations are of a very limited number of animals and furthermore are subject to considerable error inherent in satellite tracking using the Argos system (Vincent et al. 2002). Argos error would be likely to bias our estimate of the size of the foraging kernel upwards, and therefore we believe that our current estimate of $\theta$ is probably too large, consistent with the observations of Simrad. The observed sensitivity of our parameter estimates to the size of the movement kernels suggests that parameter estimates of the MSFR depend crucially on the spatial scale over which a whale is assumed to have foraged. Therefore, we argue strongly for the importance of research into the fine-scale foraging behaviour of minke whales, ideally from further telemetry-based studies or from boat follows of individual whales (Johnston et al. 2005). The scale-dependence in the MSFR parameters $m$ and Nhalf is particularly conspicuous for krill. Krill is more heterogeneously distributed on a fine spatial scale compared with capelin and herring (Dalpadado \& Skjoldal 1996), so the process of spatial sampling for $N$ may be more sensitive to the value of $\theta$ for this prey.

In the range of values we consider most plausible for $\theta$ (i.e. $1.83 \mathrm{n}$ miles or less), estimates of the parameter $m$ are $>1$. Single species predator-prey dynamics imply that, where $m>1$, a predator may generate a lowdensity equilibrium or 'predator pit' for its prey (e.g. Murdoch \& Oaten 1975, Turchin 2003); therefore, this aspect of our fitted model could potentially have important implications for the role of whales in the Barents Sea. However, it should be emphasised that the consequences of a Type III functional response in a multispecies system are difficult to interpret. The presence of other prey in the system, and the abundance of that prey, may have as much effect on the consumption rate of a fish stock of interest as the abundance of that fish itself. The shape of the 'single species' functional response to a given prey is conditional on the abundances of other prey - and, in a real ecosystem, these may vary (Murdoch \& Oaten 1975). 
Simple consumption simulations, based on the fitted MSFR, suggest that minke whales have negligible affect on local aggregations of herring and krill, whereas capelin aggregations can be greatly depleted. Apparently, minke whales appear to find capelin easier to exploit than other prey, and possible explanations for this are prey mobility, schooling behaviour and other anti-predator responses. It is well known that minke whales have a high preference for summerspawning capelin (Lindstrøm \& Haug 2001), mainly
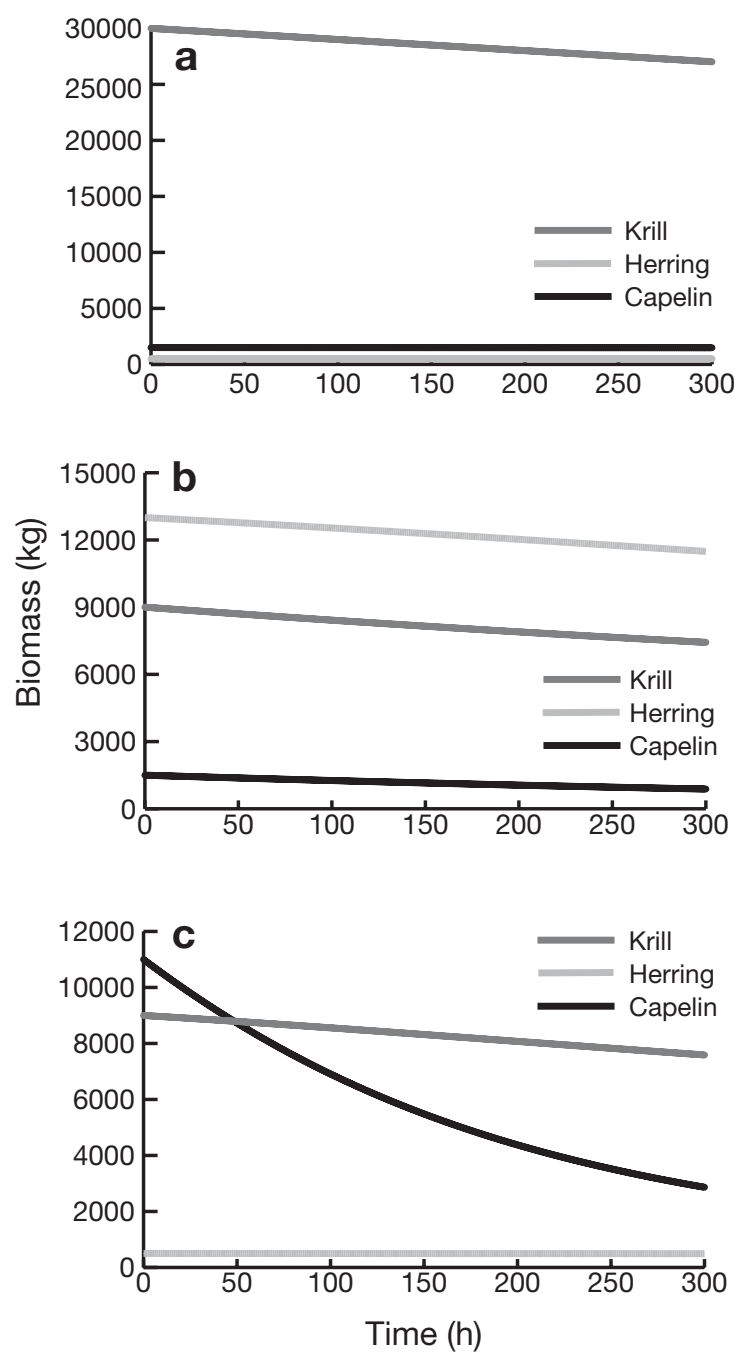

Fig. 6. Simulation of prey consumption based on the functional response model. The effect of predation on prey abundance by a single whale foraging within a $1 \mathrm{n}$ mile square is shown. Prey was assumed to be stationary in space, i.e. there was no migration of prey in or out of the area. (a) Starting values of prey abundances were set so that capelin availability was initially high, whereas availabilities of krill and herring were low. (b) Initial availability of herring was high, while availability of other prey was low. (c) Initial abundance of krill was high, whereas the abundance of other prey was low because they aggregate in dense schools at their breeding grounds (e.g. Hamre 1994) but also owing to poor anti-predator responses.

In order to understand the long-term and large-scale consequences of minke whale predation for prey stocks, more sophisticated multispecies modelling will be required that incorporates the dynamics of all important prey and, potentially, the population dynamics of the whales themselves. Although multispecies and eco-trophic models have been in existence for almost 3 decades (e.g. May et al. 1979), most fish stocks are managed at a single-species level so that important ecological processes such as inter- and intraspecific interactions are ignored. Some fish stock assessment models have incorporated ecosystem elements (e.g. Tjelmeland \& Lindstrøm 2005), but they are not able to evaluate changes in the function and structure of the ecosystem, which would be necessary in order to address wider aspects of ecosystem dynamics (e.g. Pikitch et al. 2004). Multispecies functional responses that describe the trophic relationships between species are an essential component of ecosystem models, and modelling these correctly may be of crucial importance (Yodzis 2000). However, functional responses have generally proved difficult to parameterise directly because field data for consumption are often difficult to obtain, and prey availability to predators may be difficult to measure.

We suggest that the present study addresses these key problems in 3 important ways. Firstly, dedicated prey surveys were carried out in the area and at the time when consumption was measured, i.e. the measurements of prey availability were well matched in time and space with the measurements of consumption rate. Secondly, we have begun to develop methods with which to estimate prey availability and the uncertainty in this quantity based on a realistic model of whale movement. Because the results are strongly dependent on the exact parameterisation of the whale movement model, it is clearly a priority to learn more about the details of whale foraging movements on local scales. Thirdly, by carrying out the model fitting using Bayesian methods, we were able to fit a multispecies model even when data were relatively sparse by making use of prior information. We were also able to incorporate the uncertainty in estimates of both prey availability and consumption into the fitting process. Such methods may, in future, play an important role in illuminating questions about the potential competitive interactions between marine mammal predators and fisheries.

Specification of prey consumption rates by predators on various spatial and temporal scales is critical for understanding food web dynamics (e.g. Abrams \& Ginzburg 2000). The choice of spatial scale is impor- 

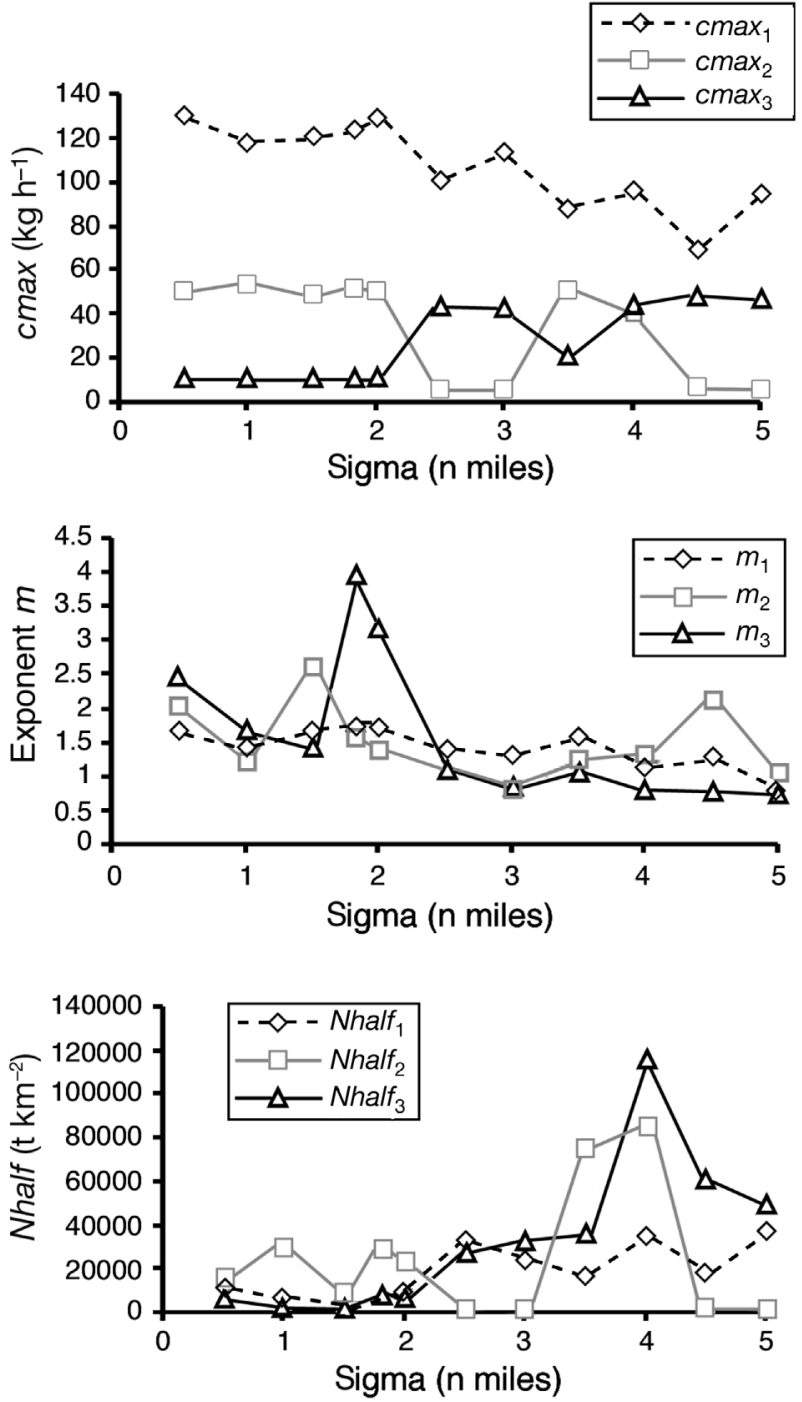

Fig. 7. Sensitivity of parameter estimates to the value of the movement kernel $\theta$. Variation in the mean of each multispecies functional response (MSFR) parameter for each species is shown

tant when performing process-oriented studies and may explain why the shape parameters $(m)$ obtained for the minke whale functional response in the study by Tjelmeland \& Lindstrøm (2005) differed from the values obtained in the present study. A likely explanation is that frequency-dependent habitat selection may play an important role in shaping the functional response of predators measured over larger scales. Previous and more recent studies suggest that baleen whales are able to track temporal and spatial changes in prey abundance (e.g. Piatt \& Methven 1992, Kann \& Wishner 1995, Reid et al. 2000). Also, recent ecological studies of northeast Atlantic minke whales (Bogstad et al. 1997, Haug et al. 2002) and sighting surveys
(Schweder et al. 1997, Skaug et al. 2004) indicate that minke whales distribute themselves according to an ideal free distribution (Fretwell \& Lucas 1969) changes in minke whales' use of prey and habitat during the past decade correlate well with changes in the abundance of their favourable prey (capelin and juvenile herring) (Haug et al. 2002). To scale up the MSFR model to fit the spatio-temporal framework of larger ecosystem models such as GADGET (Begley \& Howell 2004, see also http://www1.uni-hamburg.de/ BECAUSE/), we need to determine the aggregative response of the whales (Asseburg 2004).

We therefore suggest 2 important directions for future research into the impact of foraging by minke whales in the Barents Sea ecosystem: (1) to better determine the scale and nature of foraging movements of the whales, and to (2) develop methods for modelling the distribution of whales as a function of the distribution of their prey. Further, it will only be by modelling the dynamics of the whole ecosystem with appropriate complexity, incorporating functional and aggregative responses into an ecosystem model, that we will be able to explore the impact of consumption by minke whales on fish stocks in the Barents Sea.

Acknowledgements. S.S. was funded by the BECAUSE project (www1.uni-hamburg.de/BECAUSE). We thank colleagues J. Matthiopoulos, J. Harwood, B. Bogstad and D. Howell, and 3 anonymous reviewers for their helpful comments on the manuscript.

\section{LITERATURE CITED}

Abrams PA (1999) Is predator-mediated coexistence possible in unstable systems? Ecology 80:608-621

Abrams PA, Ginzburg LR (2000) The nature of predation: prey dependent, ratio dependent or neither? Trends Evol Ecol 15:337-341

Asseburg C, Smout S, Harwood J, Matthiopoulos J (2004) The functional response of generalist predators, and their implications for the monitoring of marine ecosystems. In: Boyd IL, Wanless S, Camphuysen K (eds) Top predators in marine ecosystems: their role in monitoring and management. Cambridge University Press, Cambridge, p 262-274

Begley J, Howell D (2004) An overview of Gadget, the globally applicable area-disaggregated general ecosystem toolbox. ICES CM 2004/FF:13. Available at: www.hafro.is/ gadget/files/overview.pdf

Bigg MA, Fawcett I (1985) Two biases in diet determination of northern fur seals (Callorhinus ursinus). In: Beddington JR, Beverton RJH, Lavigne DM (eds) Marine mammals and fisheries. George Allen \& Unwin, London, p 284-291

Bodholt H, Nes H, Solli H (1989) A new echo-sounder system. Proc Inst Acoust 11:123-130

Bogstad B, Hauge KH, Ulltang Ø (1997) MULTSPEC-a multispecies model for fish and marine mammals in the Barents Sea. J Northwest Atl Fish Sci 22:317-341

Dalpadado P, Skjoldal HR (1996) Abundance maturity and growth of the krill species Thysanoessa inermis and $T$. 
longicaudata in the Barents Sea. Mar Ecol Prog Ser 144: 175-183

Dragesund O, Johannessen A, Ulltang $\varnothing$ (1997) Variation in migration and abundance of Norwegian spring spawning herring (Clupea harengus L.). Sarsia 82:97-106

Dunbrack RS, Liguere LA (1987) Adaptive responses to accelerating costs of movement: a bioenergetic basis for the type III functional response. Am Nat 130:147-160

Foote KG, Knudsen HP, Korneliussen RJ, Nordbø PE, Røang K (1991) Postprocessing system for echo sounder data. J Acoust Soc Am 90:37-47

Fretwell SD, Lucas HL (1969) On territorial behaviour and other factors influencing habitat distribution in birds. Acta Biotheor 19:16-36

Gelman A, Carlin JC, Stern H, Rubin DB (1995) Bayesian data analysis. Chapman \& Hall, New York

Gentleman W, Leising A, Frost B, Strom S, Murray J (2003) Functional responses for zooplankton feeding on multiple resources: a review of assumptions and biological dynamics. Deep-Sea Res 50:2847-2875

Hamre J (1994) Biodiversity and exploitation of the main fish stocks in the Norwegian-Barents Sea ecosystem. Biodivers Conserv 3:473-492

Harbitz A, Lindstrøm U (2001) Stochastic spatial analysis of marine resources with application to minke whale foraging: a synoptic case study from the southern Barents Sea. Sarsia 86:485-501

Haug T, Gjøsæter H, Lindstrøm U, Nilssen KT (1995) Diets and food availability for northeast Atlantic minke whales (Balaenoptera acutorostrata) during summer 1992. ICES J Mar Sci 52:77-86

Haug T, Lindstrøm U, Nilssen KT, Røttingen I, Skaug HJ (1996) Diet and food availability for northeast Atlantic minke whales (Balaenoptera acutorostrata). Rep Int Whaling Comm 46:371-382

Haug T, Lindstrøm U, Nilsen KT (2002) Variations in minke whale (Balaenoptera acutorostrata) diet and body condition in response to ecosystem changes in the Barents Sea. Sarsia 87:409-422

Hilborn R, Mangel M (1997) The ecological detective: confronting models with data. Princeton University Press, Princeton, NJ

Hilborn R, Walters C (1992) Behaviour of exploited populations. Chapman \& Hall, New York

Hoelzel A, Dorsey EM, Stern J (1989) The foraging specializations of individual minke whales. Anim Behav 38:786-794

Holling CS (1959) Some characteristics of simple types of predation and parasitism. Can Entomol 91:385-398

IWC (International Whaling Commission) (2002) Report of the modelling workshop on cetacean-fishery competition. IWC, Cambridge

Jeschke JM, Kopp M, Tollrian R (2002) Predator functional responses: discriminating between handling and digesting prey. Ecol Monogr 72:95-112

Johnston DW, Thorne LH, Read AJ (2005) Fin whales Balaentoptera physalus and minke whales Balaentoptera acutorostrata exploit a tidally driven island wake ecosystem in the Bay of Fundy. Mar Ecol Prog Ser 305:287-295

Juliano SA (2001) Non-linear curve fitting: predation and functional response curves. In: Scheiner SM, Gurevitch J (eds) Design and analysis of ecological experiments, 2nd edn. Chapman \& Hall, New York

Kann LM, Wishner K (1995) Spatial and temporal patterns of zooplankton on baleen whales feeding grounds in the southern Gulf of Maine. J Plankton Res 17:235-262

Koen Alonso M, Yodzis P (2005) Multispecies modelling of some components of the marine community of northern and central Patagonia, Argentina. Can J Fish Aquat Sci 62:1490-1512

Kotler BP, Brown JS (1988) Environmental heterogeneity and coexistence of desert rodents. Annu Rev Ecol Syst 19: 281-307

Kotler BP, Brown JS (1999) Mechanisms of coexistence of optimal foragers as determinants of the local abundance and distributions of desert granivores. J Mamm 80: 361-374

Lindstrøm U, Haug T (2001) Feeding strategy and prey selectivity in minke whales (Balaenoptera acutorostrata) foraging in the southern Barents Sea during early summer. J Cetacean Res Manage 3:239-249

Lindstrøm U, Fujise Y, Haug T, Tamura T (1998) Feeding habits of Western North Pacific minke whales Balaenoptera acutorostrata, as observed in July-September 1996. Rep Int Whaling Comm 48:463-469

Martin TG, Wintle BA, Rhodes JR, Kuhnert PM, Field SA, Low-Choy SJ, Tyre AJ, Possingham HP (2005) Zero tolerance ecology: improving ecological inference by modelling the source of zero observations. Ecol Lett 8:1235-1246

May RM, Beddington JR, Clark CW, Holt SJ, Laws RM (1979) Management of multispecies fisheries. Science 205: 267-277

Mori Y, Boyd IL (2004) The behavioral basis for nonlinear functional responses and optimal foraging in antarctic fur seals. Ecology 85:398-410

Murdoch WW, Oaten A (1975) Predation and population stability. Adv Ecol Res 9:1-131

Neal R (1997) Markov chain Monte Carlo methods based on 'slicing' the density function. Technical Report 9722. Department of Statistics, University of Toronto

North Atlantic Marine Mammal Commission (2004) Draft report of the NAMMCO workshop 'marine mammals and fisheries in the Atlantic: estimating consumption and modelling interactions'. NAMMCO, Tromsø

Pech RP, Sinclair ARE, Newsome AE, Catling PC (1992) Limits to predator regulation of rabbits in Australia-evidence from predator-removal experiments. Oecologia 89: $102-112$

Piatt JF, Methven DA (1992) Threshold foraging behaviour of baleen whales. Mar Ecol Prog Ser 84:205-210

Pikitch EK, Santora C, Babcock EA, Bakun A and 13 others (2004) Ecosystem-based fishery management. Science 305:346-347

Real LA (1977) The kinetics of functional response. Am Nat 111:289-300

Real LA (1979) Ecological determinants of functionalresponse. Ecology 60:481-485

Redpath S, Thirgood S (1999) Numerical and functional responses in generalist predators: hen harriers and peregrines on Scottish grouse moors. J Anim Ecol 68:879-892

Reid K, Brierley AS, Nevitt GA (2000) An initial examination of relationships between the distribution of whales and Antarctic krill (Euphausia superba) at South Georgia. J Cetacean Res Manage 2:143-149

Rindorf A, Gislason H (2005) Functional and aggregative response of North Sea whiting. J Exp Mar Biol Ecol 324:1-19

Sakshaug E, Bjørge A, Gulliksen B, Loeng H, Mehlum F (1994) Structure, biomass distribution, and energetics of the pelagic ecosystem in the Barents Sea: a synopsis. Polar Biol 14:405-411

Schweder T, Skaug HJ, Dimakos XK, Langaas M, Øien N (1997) Abundance of northeastern Atlantic minke whales, estimates for 1989 and 1995. Rep Int Whaling Comm 47: $453-483$ 
Schweder T, Hagen G, Hatlebakk E (1998) On the effect on cod and herring fisheries of returning revised management procedure for minke whales in the Greater Barents Sea. Fish Res 37:77-95

Simrad Y, Lavoie D, Saucier FJ (2002) Channel head dynamics: capelin (Mallotus villosus) aggregation in the tidally driven upwelling system of the Sanguenay St Lawrence Marine Park's whale feeding ground. Can J Fish Aquat Sci 59:197-210

Skaug HJ, Øien N, Bøthun G, Schweder T (2004) Abundance of northeastern Atlantic minke whales for the survey period 1996-2001. Can J Fish Aquat Sci 61:870-886

Tjelmeland S, Lindstrøm U (2005) An ecosystem element added to the assessment of Norwegian spring spawning herring: implementing predation by minke whales. ICES J Mar Sci 62:285-294

Trexler JC, McCulloch CE, Travis J (1988) How can the functional response best be determined? Oecologia 76: 206-214

Turchin P (1998) Quantitative analysis of movement: measuring and modelling population redistribution in animals and plants. Sinauer Associates, Sunderland, MA

Editorial responsibility: Howard Browman (Associate Editorin-Chief), Storebø, Norway
Turchin P (2003) Complex population dynamics, a theoretical/ empirical synthesis. Princeton University Press, Princeton, NJ

van Baalen M, Privan V, van Rijn PCJ, Sabelis MW (2001) Alternative food, switching predators, and persistence of predator-prey systems. Am Nat 157:512-524

Vincent TLS, Scheel D, Brown JS, Vincent TL (1996) Tradeoffs and coexistence in consumer-resource models: it all depends on what and where you eat. Am Nat 148: 1038-1058

Vincent C, McConnell BJ, Ridoux V, Fedak M (2002) Assessment of Argos location accuracy from satellite tags deployed on captive gray seals. Mar Mamm Sci 18: 156-166

Wood S (2000) Modelling and smoothing parameter estimation with multiple quadratic penalties. J R Stat Soc B 62: 413-428

Yodzis P (1998) Local trophodynamics and the interactions of marine mammals and fisheries in the Benguela ecosystem. J Anim Ecol 67:635-658

Yodzis P (2000) Diffuse effects in food webs. Ecology 81: 261-266

Submitted: July 18, 2006; Accepted: November 23, 2006

Proofs received from author(s): June 8, 2007 